\title{
Convective-scale responses of a large-domain, modelled tropical environment to surface warming
}

\author{
Matthew R. Igel, ${ }^{\mathrm{a} *}$ Susan C. van den Heever, ${ }^{\mathrm{a}}$ Graeme L. Stephens ${ }^{\mathrm{b}}$ and Derek J. Posselt ${ }^{\mathrm{c}}$ \\ ${ }^{a}$ Department of Atmospheric Science, Colorado State University, Fort Collins, CO, USA \\ ${ }^{\mathrm{b}}$ Jet Propulsion Laboratory, Pasadena, CA, USA \\ ${ }^{\mathrm{c}}$ Department of Atmospheric, Oceanic, and Space Sciences, University of Michigan, Ann Arbor, MI, USA
}

${ }^{\star}$ Correspondence to: M. R. Igel, Department of Atmospheric Science, 1371 Campus Delivery, Fort Collins, CO 80523-1371, USA. E-mail: MattIgel@atmos.colostate.edu

\begin{abstract}
This article explores the response of convective-scale atmospheric characteristics to surface temperature through the lens of large-domain, cloud-system-resolving model experiments run at radiative convective equilibrium. We note several features reminiscent of the response to surface warming in atmospheric general circulation models. These include an increase in the rain rate that is smaller than the modelled increase in precipitable water, a systematic decrease in sensible heating and an increase in clear-sky cooling. However, in contrast to climate models, we note that tropospheric relative humidity increases and columnintegrated water vapour increases at the rate anticipated from the Clausius-Clapeyron relationship, but only when compared with the troposphere mean temperature rather than surface temperature. Also shown are results elucidating the changes in the vertically integrated water budget and the distribution of high precipitation rates shifting toward higher rates. Moist static energy distributions are analyzed and, from these, clouds are implicated in effecting the final equilibrium state of the atmosphere. The results indicate that, while there are aspects of the tropical equilibrium that are represented realistically in current general circulation model climate-change experiments, there are potentially influential local interactions that are sufficiently important as to alter the mean response of the tropical water and energy balance to changes in sea-surface temperature. Convection is shown to dictate the equilibrium state across all scales, including those unresolved in climate models, rather than only responding to surface-induced changes.
\end{abstract}

Key Words: convection; climate; cloud-resolving models

Received 22 October 2012; Revised 2 July 2013; Accepted 8 July 2013; Published online in Wiley Online Library 30 September 2013

\section{Introduction}

There are a number of important and common responses revealed in the climate-warming experiments performed by the Intergovernmental Panel on Climate Change (IPCC) Fourth Assessment Report (AR4) general circulation models (GCM). These include the following.

(i) The relative humidity remains approximately invariant with respect to climate forcing (e.g. Allen and Ingram, 2002; Vecchi and Soden, 2007; Richter and Xie, 2008, among others) except, perhaps, locally in response to changes in the large-scale circulation (Sherwood et al., 2010). This behaviour is fundamental to the warming projected by these models via the way it establishes the strength of the water-vapour feedback (e.g. Held and Soden, 2000) and patterns of precipitation minus evaporation (Seager et al., 2010). As a consequence, increases in absolute humidity closely follow the Clausius-Clapeyron (CC) relation, increasing at approximately $7 \% \mathrm{~K}^{-1}$ (Allen and
Ingram, 2002; Held and Soden, 2006; Stephens and Ellis, 2008). Long-term observations of surface relative humidity also apparently support this response (Willett et al., 2007) as do the observations of column water vapour from satellite microwave radiometers (Santer et al., 2007). There is less certainty, however, about how relative humidity of the upper troposphere might change with climate change and it is now well recognized that small changes in upper tropospheric humidity can amplify or dampen the watervapour feedback (Soden et al., 2005; Paltridge et al., 2009).

(ii) There has been much discussion about whether or not the global hydrological cycle is expected to accelerate with global warming. Recent discussion on this topic usually centres on the proportional rates of change of precipitation relative to the rates of change of water vapour projected in global warming climate model simulations (e.g. Wentz et al., 2007; Stephens and $\mathrm{Hu}, 2010$ ). The global-mean precipitation rate increases at a rate of about $1-2 \%$ per degree of surface global warming in global 
climate models, in direct contrast to the increase in water vapour (Allen and Ingram, 2002; Held and Soden, 2006; Pall et al., 2007). Although there is an expectation that the global precipitation should follow the global water-vapour increase (e.g. Trenberth et al., 2005; Wentz et al., 2007), Stephens and Ellis (2008) clearly demonstrate why this is unlikely on the global scale given that the controlling influence of water vapour on global precipitation actually occurs via its influence on the radiative budget of the atmosphere, predominantly through infrared emission from the atmosphere. They further showed that the approximately $2 \%$ per degree of surface global warming is what is expected from the controlling influence of this emission process.

(iii) In warmer periods, the probability density function (PDF) of precipitation shifts to slightly more intense rainfall events in global models (e.g. Pall et al., 2007; Liu et al., 2012), in the real climate system (Groisman et al., 2005; Zhang et al., 2007) and, apparently, in conditions of warmer sea-surface temperature (SST: Rondanelli and Lindzen, 2008). Although broad global-scale changes to precipitation appear to come under the influence of robust radiation controls, changes to the regional character of precipitation (frequency, organization and intensity) and the processes that determine them are not as obviously controlled nor understood. For example, Pall et al. (2007) show how the daily precipitation rate associated with the heaviest precipitation events increases in a warmed climate by an amount similar to the column water-vapour change. The rationale for this is that these more intense storms come under the local influences of moisture convergence, which might be expected to vary with the $7 \% \mathrm{~K}^{-1}$ CC water-vapour change.

It is worth testing the realism of such findings when drawn from present-day climate models. Even accepting such responses at face value, a quantitative understanding of why such changes occur as they do is currently lacking. A deeper understanding of what processes shape them ((i)-(iii)) and why they occur will eventually lead to improved ways of representing these critical processes in models of climate change and inevitably lead to greater confidence in climate-change projections.

It will be shown that including the connection between convection and the energy budget of the Earth in more detail than is represented in present-day climate models is fundamental to developing our understanding of the kinds of responses described above. Many of the important processes that are expected to crosscut the responses described above involve convection. Convection affects the amount of water vapour that is evaporated from ocean surfaces through the turbulence associated with it and thus is central to water-vapour feedback. Convection also affects the upper tropospheric humidity by detrainment and evaporation of condensate (e.g. Soden and Fu, 1995). It also controls the vertical distribution of clouds and thus indirectly the radiative heating associated with them (Stephens and Ellis, 2008). Convection effectively redistributes energy through localized upward vertical motion, through distribution of moisture and through latent heating of condensation and fusion. These convective processes and their statistical distributions are difficult (if not impossible) for current GCMs to simulate accurately, given that their grid resolution requires convection to be parametrized. For example, it has been shown that convective mass flux is characteristically different in GCMs and cloud-resolving models (Yano et al., 2004). While climate models should do a good job of simulating the mean of the physics accurately, the distribution about the mean may not necessarily be representative of nature. The means are strongly constrained, but the distributions are not.

The purpose of this article is to determine the extent to which responses (i)-(iii) appear in radiative-convective equilibrium (RCE) experiments and to use these experiments to elucidate mechanisms that can explain responses that do occur in reality. It is not the goal here to rebut GCM results, but to add an additional perspective from the impact of scales currently unachievable in GCMs. The experiments reported in this article are performed using a state of the art cloud-system-resolving model that is integrated over a large model domain and over periods long enough that a state of radiative convective equilibrium is established. The rationale for such experiments is described in more detail in Stephens and Ellis (2008). In these simulations, convective systems are resolved (at least marginally), thus eliminating the need for the use of a convection parametrization scheme. The numerical experiments are designed to explore the sensitivity of the RCE state to changes in the imposed climate state as defined by different underlying fixed SSTs. There is much insight to be gained from such simple experiments, given that the factors that organize and influence convection in the real atmosphere, especially on the time-scales pertinent to RCE, are not well understood and, as will be shown, influence the entirety of the equilibrated atmospheric state.

In a previous article (Posselt et al., 2012), the influence of the interaction between deep convective cloud systems and the convective environment was examined. In this work, a more system-wide view will be taken in examining gross influences on the domain-mean equilibrium state and noting, when relevant, the mechanisms involving convection that help to dictate the mean state. Here, the importance of convection and its explicit representation in these simulations, in not only responding but also helping to modulate the mean state atmosphere and how this changes with surface warming, is assessed.

\section{Model description and experimental set-up}

\subsection{Model description}

The model used in the experiments reported in this article is the Regional Atmospheric Modelling System (RAMS: Cotton et al., 2003; Saleeby and van den Heever, 2013) developed at Colorado State University. RAMS is a non-hydrostatic, cloud-systemresolving model that incorporates sophisticated microphysics, radiation, surface and turbulence schemes. The model integrates predictive equations for the three wind components, the Exner function, ice liquid potential temperature and total mixing ratio on a vertically stretched Arakawa $\mathrm{C}$ grid. The RAMS advection scheme, turbulence, radiation, cloud microphysics and surface flux parametrizations are documented in Cotton et al. (2003) and Saleeby and Cotton (2004) and a detailed description of recent changes to the model microphysics can be found in Saleeby and van den Heever (2013). For the simulations conducted here, the surface processes were parametrized using the Land Ecosystem-Atmosphere Feedback-2 (LEAF-2: Walko et al., 2000), turbulence is represented by the Smagorinsky (1963) deformation-K closure scheme with stability modifications by Lilly (1962) and Hill (1974) and solar and infrared radiative fluxes by the two-stream radiation scheme of Harrington (1997). There is no rotation or large-scale forcing in these simulations. Finally, four damping layers were included below the model top.

\subsection{Experimental set-up}

Questions raised in past cloud-resolving model RCE experiments are relevant to the design of the experiments reported in this study. To address concerns about the possible effects of two-dimensional geometry, imposing scales of organization of convection that are artificially larger than the characteristic scale of three-dimensional (3D) convection (e.g. Tompkins, 2000; Stephens and Ellis, 2008), we conduct experiments in 3D. To address concerns about the use of $3 \mathrm{D}$ domains restricted to just a few hundred kilometres in scale, we adopt the channel-mode configuration as originally introduced by Tompkins (2001) and employed in the study of Stephens and Ellis (2008). This configuration represents a compromise between the need for a $3 \mathrm{D}$ 
domain large enough not to trivially constrain the behaviour of the convective ensemble, yet small enough to meet limitations of available computer resources. The $3 \mathrm{D}$ channel experiments performed employ a domain of 4000 points in the 'zonal' direction and 75 grid points in the 'meridional' direction, thus covering an area of approximately $1728000 \mathrm{~km}^{2}(9600 \mathrm{~km} \times 180 \mathrm{~km})$. Horizontal grid spacing is $2.4 \mathrm{~km}$. There are 37 vertical levels weighted to the lower atmosphere and extending to just below $26 \mathrm{~km}$. The experiments are run for 55 days, approximately 25 of which are beyond model equilibration (see the next section). Time-mean values referenced in figures, tables and discussion are averaged during the final 10 days. Given the well-equilibrated nature of the simulations in the final 10 days, results are highly insensitive to the precise length of averaging time.

All experiments are initialized with the 0000 UTC 5 December 1992 Coupled Ocean-Atmosphere Response Experiment of the Tropical Ocean and Global Atmosphere Programme (TOGA COARE) sounding with initially zero mean wind in the vertical. The SSTs are held constant at 298, 300 and $302 \mathrm{~K}$ (experiments termed SST298, SST300 and SST302). Solar insolation is held constant at $447 \mathrm{~W} \mathrm{~m}^{-2}$ and thus there is no diurnal cycle. Singlemoment bulk microphysics are employed. A constant profile of $\mathrm{CO}_{2}$ is used. As such, these models are not a perfect proxy for global warming conditions, as the distribution of $\mathrm{CO}_{2}$ will affect tropospheric stability and thus the population of convection. However, our set-up should demonstrate the physics that are generally relevant to understanding sensitivities to SST. A more complete discussion of the model and the experimental set-up is contained in Stephens and Ellis (2008) and Posselt et al. $(2008,2012)$

\section{The nature of radiative-convective equilibrium}

Figure 1 illustrates the time-mean, meridional mean of columnintegrated water vapour (PW) for SST298 and SST302 and demonstrates the first-order characteristics of the RCE reached. It provides a glimpse of how the water cycle of the model is grossly organized into wet and dry regions. These remain more or less coherent and almost stationary in space during the forward integration of the experiments. It also shows the increase in mean PW from $29.19 \mathrm{~mm}$ in SST298 to $47.95 \mathrm{~mm}$ in SST302. The nature of similar equilibrium structures and factors affecting convective organization have been discussed in past studies (e.g. Held et al., 1993; Grabowski and Moncrieff, 2001; Tompkins, 2001; Bretherton et al., 2005, among others). More detailed analysis of how this organization is altered with changing SST is provided in Posselt et al. (2012).

It has been documented elsewhere that the simulated convection embedded within these moist regions of high PW exhibit many of the characteristics of real tropical convection, including a trimodal cloud distribution (van den Heever et al.,

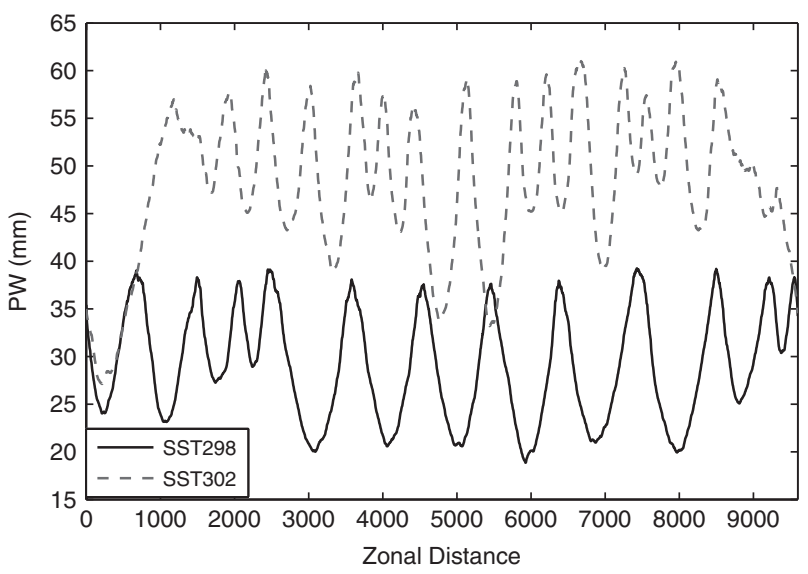

Figure 1. Mean meridional, time-mean zonal PW at equilibirum. SST298 is shown by the solid line and SST302 by the dashed one. Means are taken during the final 10 days.
Table 1. Properties at equilibrium: means of net all-sky and clear-sky radiation, surface fluxes, precipitable water quantities, bulk relative humidity, rain rate and tropospheric mean temperature, plus percentage differences per degree $\mathrm{K}$ of warming from SST300 of precipitable water quantities and rain rate. Means are taken over the entire domain during the final ten model days.

\begin{tabular}{lccc}
\hline & SST298 & SST300 & SST302 \\
\hline $\mathrm{R}_{\text {net }}\left(\mathrm{W} \mathrm{m}^{-2}\right)$ & -79.36 & -83.14 & -86.90 \\
$R_{\text {net clr }}\left(\mathrm{W} \mathrm{m}^{-2}\right)$ & -109.77 & -117.91 & -121.98 \\
$\mathrm{LH}\left(\mathrm{W} \mathrm{m}^{-2}\right)$ & 68.83 & 74.69 & 79.33 \\
$\mathrm{SH}\left(\mathrm{W} \mathrm{m}^{-2}\right)$ & 9.78 & 8.81 & 7.91 \\
$\mathrm{PW}(\mathrm{mm})$ & 29.19 & 37.73 & 47.95 \\
$\mathrm{PW}$ thresh $(\mathrm{mm})$ & 33 & 44 & 53 \\
$\mathrm{RH}^{*}(\%)$ & 62 & 65 & 66 \\
$\left.\mathrm{RR}(\mathrm{mm} \mathrm{h})^{-1}\right)$ & 4.45 & 4.85 & 5.06 \\
$\% \mathrm{PW} 300(\mathrm{~K})$ & -11.3 & - & 13.5 \\
$\% \mathrm{PW}$ thresh $300(\mathrm{~K})$ & -12.5 & - & 10.2 \\
$\% \mathrm{RR} 300(\mathrm{~K})$ & -4.5 & - & 2.2 \\
Mean temp $(\mathrm{K})$ & 264 & 269 & 273 \\
\hline
\end{tabular}

2011) and a prominent freezing-level stable layer (e.g. Posselt et al., 2008). The simulations also exhibit evidence of mid-level entrainment in actively convecting regions, with detrainment maximized below the (approximate) trade wind inversion and the freezing level and in the upper troposphere. The details of how the mesoscale organization of convection changes with increasing SST is the focus of Posselt et al. (2012), and these changes occur in a way that is not entirely predictable. This is hinted at in Figure 1 by the way the moist-dry spatial structure in the $302 \mathrm{~K}$ experiment is different in horizontal scale from the equilibrium state of SST298. Unlike the broad rising motion and trimodal distribution of the moist regions, regions of low PW exhibit frequent boundary-layer cumulus clouds with weak, troposphere-deep subsidence above. Changes to the large-scale circulation have been associated with variations in the boundary-layer cloud fraction of these dry bands (van den Heever, 2011; Storer and van den Heever, 2013). For a reference population density of PW for each simulation, the reader is referred to Figure 5 later.

Table 1 summarizes some average responses of the system in equilibrium for the three experiments conducted with different SSTs. The table lists domain-mean values of key quantities averaged over the last 10 days of a 55 day integration that characterize the state of RCE. Equilibrium is declared to be have been reached in these experiments when the net radiative heating of the atmosphere $\left(R_{\text {net }}\right)$ is balanced by the thermal heat flux $(\mathrm{THF}=\mathrm{LH}+\mathrm{SH})$ within $1-2 \mathrm{~W} \mathrm{~m}^{-2}$. This has occurred for all three experiments after approximately a month of integration. The data are grouped into three broad categories. The first four quantities include the domain-mean energy-budget fluxes and related quantities. The next four entries list different variables that characterize the hydrological cycle, including the domain-averaged column water vapour (PW), a threshold value of water vapour $\left(\mathrm{PW}_{\text {thresh }}\right)$ to be described in the next section, the column-mean relative humidity $\left(\mathrm{RH}^{\star}\right.$ : $\mathrm{PW}$ scaled by saturated PW, Bretherton et al., 2004) and the domain-mean rain rate (RR) as defined later. The next three parameters are the fractional change per degree of surface warming in $\mathrm{PW}, \mathrm{PW}_{\text {thresh }}$ and RR between the 298 and 302 K SST equilibrium states and the 'control' $300 \mathrm{~K}$ SST state. The final row lists the pressure-weighted tropospheric mean temperature, which is calculated as in Neelin et al. (2009) between the surface and $200 \mathrm{hPa}$. This quantity will be related to other troposphere-deep quantities.

We note the following regarding these tabulated results.

(i) The model produces a systematic decrease in $\mathrm{SH}$ flux with increasing SST. The approximate decrease of $-6 \% \mathrm{~K}^{-1}$ is similar in magnitude to the decreased fluxes in the IPCC model projections (e.g Stephens and Ellis, 2008).

(ii) The LH flux systematically increases with SST at approximately $3 \% \mathrm{~K}^{-1}$ of surface warming, and, as evidenced later in Figure 5 by much of the total evaporation 
occurring at PW values typical of clear sky, the fundamental driving force of this averaged increase is the systematic increase in the clear-sky radiative cooling of the atmosphere or equivalently, at equilibrium, the increase in long-wave (LW) radiation to the surface (e.g. Stephens and $\mathrm{Hu}, 2010$ ). Note that (i) and (ii) combine to imply a change in the mean Bowen ratio.

(iii) The all-sky radiative cooling increases with SST but at a rate less than that of the clear sky only. This is because of the increase in high clouds and the nonlinear response thereof to increasing SST (Igel, 2011; Luo et al., 2012).

(iv) The clear-sky cooling increases more between SST298 and SST300 than it does between SST300 and SST302. This difference can be attributed to a relatively constant uppertropospheric clear sky RH between SST298 and SST300 but a modest increase at upper levels between SST300 and SST302. In Posselt et al. (2012), this was attributed to an increase in water vapour at the expense of ice at these levels.

(v) The increase in $\mathrm{RH}^{*}$ with increased SSTs implies an amplified water-vapour feedback that produces a change in PW of $11.3 \% \mathrm{~K}^{-1}$ from $298-300 \mathrm{~K}$ and $13.5 \% \mathrm{~K}^{-1}$ from $300-302 \mathrm{~K}$ that is approximately $50 \%$ and nearly $100 \%$ higher, respectively, than the change predicted purely by the CC relation for changes in surface temperature near $300 \mathrm{~K}$. These values are close to some of the local changes in PW noted in O'Gorman and Muller (2010), although in the Tropics their values in the mean do not exceed $9 \% \mathrm{~K}^{-1}$. However, when the tropospheric mean temperature difference is used instead of the surface temperature difference, the increase in column water vapour is 7.45 and $6.81 \% \mathrm{~K}^{-1}$ for SST298-SST300 and SST300-SST302, respectively. It seems to be that the mean temperature constrains the column total PW better because of a near-constant increase per level of PW between simulations up to the middle troposphere. While tropospheric control makes physical sense on its own for such a shift, it will also be mentioned that this shift per level does not extend uniformly to the surface and so does not appear to be controlled only by SSTs. It is reiterated here that the mean temperature is mass-weighted and so its calculation should parallel the water-vapour profile decrease with height. This combination of warmer troposphere and elevated values of $\mathrm{RH}$ provide enhanced water-vapour feedback in comparison with the watervapour feedback of AR4 models per degree of SST warming. This enhanced feedback results from the influence of convection feeding upscale to the basic state atmosphere. This is one of the more intriguing characteristics of the simulations.

(vi) The mean intensity of rain (rain rate) also increases with SST but at a rate that is significantly less than the column water-vapour change: 4.5 and $2.2 \% \mathrm{~K}^{-1}$ of surface warming for SST298-SST300 and SST300-SST302, respectively. This feature again is similar in character to the AR4 climatechange experiments (Allen and Ingram, 2002). Although the magnitudes of the rain rate changes are more than $50 \%$ larger than those of the AR4 experiments when defined with respect to SST, the changes are in fact of similar magnitude to the AR4 results when defined with respect to the tropospheric mean temperature difference (vii).

(vii) The tropospheric mean temperature defined between the surface and $200 \mathrm{hPa}$ as in Neelin et al. (2009) increases by more than the surface temperature. This will be discussed next.

The vertical structure of the differences in the temperature and RH will also be mentioned here. Figure 2 shows these domainmean temperature profiles for SST298 and SST302. For clarity, the SST300 profile is omitted from Figure 2 and from other figures, as the trends with increasing SST are monotonic. A priori, one may
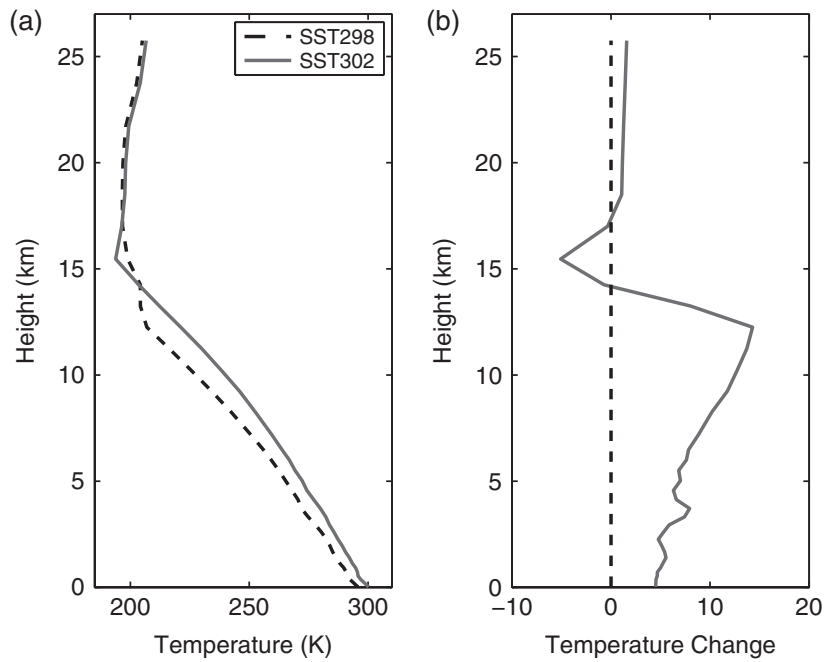

Figure 2. (a) Vertical profiles of domain- and time-averaged temperature from SST298 (dashed) and SST302 (solid). (b) Vertical profile of the averaged temperature differences (SST302-SST298). Positive numbers indicate heights at which the simulation is warmer in SST302.

assume that since SST changes, the profile of temperature must also change (at least near the surface). Indeed surface temperature does increase from SST298 to SST302, but the way in which the entire column changes is more complex. The profiles are broadly similar, with a few notable differences. The first is the increase in temperature in the lower atmosphere which is similar to the SST increase. The second is the fact that the increase is greater in the upper troposphere $(9-13 \mathrm{~km})$ than in the lower. This is due to the change with surface temperature of the shape of the pseudo-adiabatic temperature profile, which provides a lower limit to domain-mean, vertical temperature gradients at any level. This sort of result is typical in GCMs (Meehl et al., 2007) and is not surprising. It can also be seen from this figure that the cold point, an estimate of the tropopause or transition from the active troposphere to the stable stratosphere, is significantly higher in SST302. The troposphere is $12 \mathrm{~km}$ deep in SST298 and $15 \mathrm{~km}$ deep in SST302. A potential caveat to these values is the reduced vertical resolution at these heights in the domain. However, the deepening appears robust across many quantities even if the exact value of the tropopause height may not be, although we have no evidence to suggest that it is not. These findings are not new, but it is encouraging to see that the simulations perform as would be expected.

Unlike temperature, we do not know a priori how $\mathrm{RH}$ will change with SST, despite the fact it remains approximately
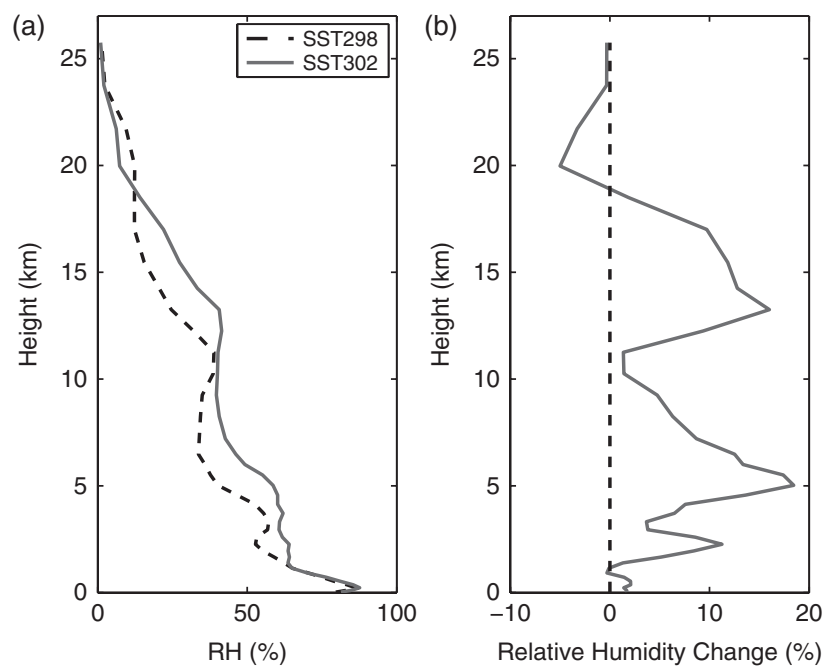

Figure 3. (a) Vertical profiles of relative humidity for SST298 (dashed) and SST302 (solid). (b) Vertical profile of the change in RH with SST. 
constant in global climate model simulations of warming. Figure 3 shows that in these idealized simulations RH does not remain constant. It demonstrates that, while the shape of the $\mathrm{RH}$ profile retains most of its features while shifting vertically due to the deeper troposphere, the values of RH are higher in SST302 at almost all levels, resulting in an increase in $\mathrm{RH}^{\star}$ (Table 1) with SST. The peak differences appear to occur around the three mean detrainment levels of the trimodal distribution of clouds (Johnson et al., 1999; Posselt et al., 2008). There is both cause and effect in this occurrence, as detrained clouds serve as a moisture source but, especially in the upper troposphere, the peak in $\mathrm{RH}$ also influences the detrainment (Hartmann and Larson, 2002; Igel, 2011). Thus, it makes intuitive sense that the tropospheredeep increase in $\mathrm{RH}$ is the result of enhanced detrainment in SST302. It was found in Posselt et al. (2012) that such cloud processes governed many aspects of the layer-local saturation fraction in these simulations. This is a particularly appealing explanation, given that detrainment is one of the primary ways in which convection communicates energy and water with the clear-sky atmosphere. Given the influence of convection on the total, vertical energy distribution (of which moisture location is a part) within the atmosphere, this result hints at the different magnitude to which convection affects the mean state of each model run (see section 6). The spatial standard deviation of RH in both simulations is approximately $20 \%$ at levels above the boundary layer and below the mean upper tropospheric outflow height and falls to zero outside this region.

However, it may be that this increase in $\mathrm{RH}$ is a fundamental result. To begin this discussion, it is useful to define a new quantity, precipitation potential energy (PPE). A single value of PPE will define an entire environment and its calculation will utilize mean profiles like those shown above. PPE shall be defined as

$$
P P E=R_{\mathrm{d}} \int_{1000 \mathrm{hPa}}^{100 \mathrm{hPa}} T_{\mathrm{v}}^{\mathrm{sp}}-T_{\mathrm{v}}^{\mathrm{ep}} \mathrm{d} \ln \left(p^{\mathrm{ep}}\right)
$$

where the superscript 'ep' is taken to be the mean profile of an environment of that quantity, the superscript 'sp' is an idealized moist profile defined by the SST of that quantity, $T_{v}$ is virtual temperature, $p$ is pressure and $R_{d}$ is the dry-air gas constant. Upon substituting for virtual temperature, assuming the environmental temperature is that of the moist adiabat (as above) and rearranging,

$$
P P E=R_{\mathrm{d}} \int_{1000 \mathrm{hPa}}^{100 \mathrm{hPa}} T^{\mathrm{sp}} \times 0.61 \times w_{\mathrm{s}}^{\mathrm{sp}} \times\left(1-R H^{\mathrm{ep}}\right) \mathrm{d} \ln \left(p^{\mathrm{ep}}\right)
$$

where $w_{\mathrm{s}}$ is the saturation mixing ratio and $\mathrm{RH}$ is the relative humidity. While PPE and convective available potential energy (CAPE), are clearly related quantities, they are not the same. PPE has been defined as a purely mean environmental quantity. CAPE is a local quantity defined for a particular column of air.

Physically, what does this quantity represent? PPE is imagined to be the ability of the mean atmosphere to warm its virtual temperature due to net condensation of rainwater. Warming can only occur if the environmental is cooler than the saturated virtual temperature (Eq. (1)). Equivalently, PPE is the total precipitation energy (or equivalently mass) occurring in an environment in equilibrium due to subsequent LW virtual cooling. Precipitation occurs in such an environment because LW cooling removes energy from the atmosphere that was generated by condensation. $\mathrm{LW}$ radiation cools the $T_{\mathrm{v}}$ profile away from the saturated value (Eq. (1)) back to the environmental value. Since LW increases with SST in the RCE simulations, so too does PPE. This process is illustrated in Figure 4(a). It is similar to the thought experiment for RCE itself: radiation cools and convection warms. Equation (2) shows how the PPE increase constrains the mean environmental profiles. The RH is the only free parameter, which fits in this framework because the moisture is assumed inherently to be the working fluid. PPE is an idealized quantity but is mechanistically informative.

Thought of differently, PPE could be imagined to result from an atmosphere, fed by surface fluxes, always being saturated and moist adiabatic in the absence of LW cooling. With the addition of LW cooling and therefore PPE, the mean profile can cool virtually and precipitate convectively. The new environment represents a balance between LW cooling and convective warming.

It has already been stated that surface precipitation, or equivalently PPE, increases at approximately $3 \% \mathrm{~K}^{-1}$ of surface warming between SST298 and SST302. The tropospheric mean temperature increases by about $1 \% \mathrm{~K}^{-1}$. The CC relation implies that the saturated mixing ratio will increase at roughly $7 \% \mathrm{~K}^{-1}$. If these constrained variables (PPE or precipitation, $T$ and $w_{\mathrm{s}}$ ) and their respective rates of increase with SST are inserted and (a)

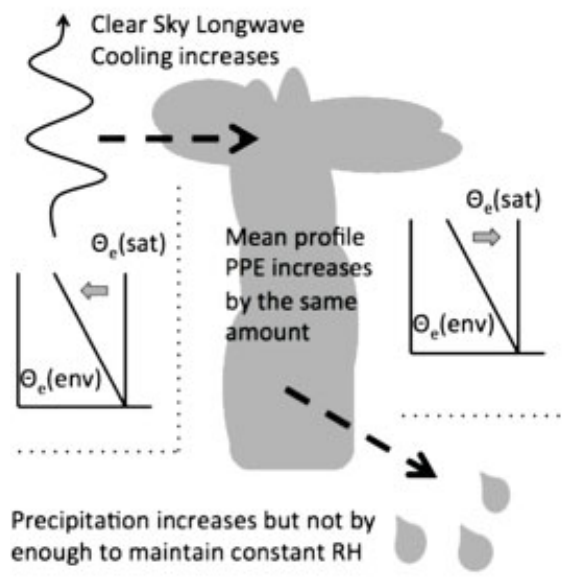

(b) $\mathrm{RH} \cdots \cdot$

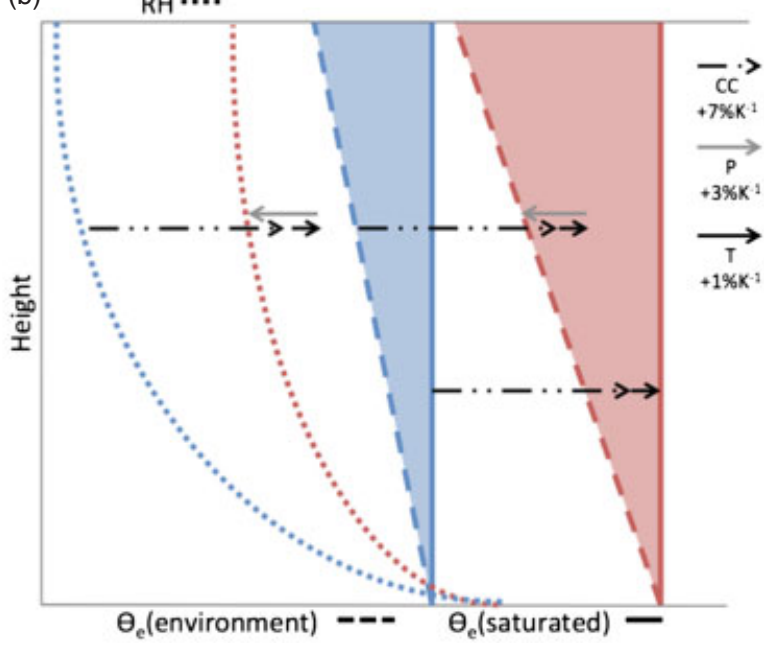

Figure 4. (a) Physical processes related to RH increase and mean PPE. Long-wave cooling increases with SST and serves to destabilize the mean atmosphere. Convection increases to eliminate mean PPE and stabilizes the mean atmosphere. Rain results from PPE release and increases with SST, but too slowly to maintain constant RH (see text). (b) Representative mean quantities for a cooler state in blue and a warmer state in red. Solid lines show the theoretical profile of saturated $\theta_{\mathrm{e}}$ and the dashed lines show the actual environmental $\theta_{\mathrm{e}}$. The shaded area between the lines is the domain-mean PPE. Horizontal arrows show physical trends between the simulations, with dashed-double dot indicating the contribution from the CC rate, grey that from the precipitation increase and black that from temperature. Trends are shown with respect to surface temperature increases. The dotted lines illustrate the resultant environmental humidity. The figure is illustrative and is not meant to be precisely quantitative. 
equated, then it can be shown that RH for SST302 must be approximately $10 \%$ higher than in SST298. This arises physically from a certain mass of water being rained out (the PPE value), not from a certain percentage of available water. Therefore, as SSTs increase, radiation implies through its control of precipitation and therefore mean PPE an increase in the domain mean RH. These trends are shown in an idealized manner in Figure 4(b). The figure is meant to indicate the constraints imposed on the mean $\mathrm{RH}$ by the trends in the physics controlling it with increasing SST. Finally, these arguments probably point to the reason that tropospheric mean temperature seems to exert a stronger control on precipitation increases than surface temperature.

This argument may also be made in terms of energies. If the SST298 and SST302 atmospheres in equilibrium are thought of as systems in which radiative cooling removes energy and convection replaces this loss and is totally converted to potential and kinetic energy then, since the strength of the convective overturning circulation decreases with increasing SST (Posselt et al., 2012), less kinetic energy is generated by the system. Because radiative cooling increases, this result implies unambiguously that more energy must be converted to potential energy. The internal (temperature component) and centre-ofmass (mechanical potential component) energies only increase slightly per degree of SST. Therefore, in SST302, much more potential energy must be stored in the chemical potential form (water vapour). Using the same estimations as above would imply an increase in chemical potential of greater than suggested by the $\mathrm{CC}$ rate. In other words, $\mathrm{RH}$ must increase.

\section{The water-vapour budget}

As a step toward understanding the nature of the enhanced moistening that occurs in these RCE experiments (compared with climate-change experiments), we first examine in detail the nature of the water balance that is established in each experiment.
The water budget can be written in the form

$$
\partial_{t} \int_{z_{\mathrm{b}}}^{z_{\mathrm{t}}} \rho q \mathrm{~d} z=-\int_{z_{\mathrm{b}}}^{z_{\mathrm{t}}} \nabla_{H}(\rho q \mathbf{u}) \mathrm{d} z+E-P,
$$

where $\nabla_{H}$ is the horizontal gradient, $\mathbf{u}$ is the horizontal wind vector and $E$ and $P$ are the rates of evaporation and precipitation, respectively. The integration bounds are from the surface to the model top. The left hand side of Eq. (3) represents the PW storage term, which may vary significantly locally but is zero under equilibrium conditions when averaged over the entire domain. The first term of the right-hand side of Eq. (3) represents the advective contributions (ADV) and the divergence contributions (DIV) of water vapour to the overall vertically integrated horizontal water-vapour flux convergence. Because of the doubly periodic boundary conditions, ADV plus DIV should integrate to zero in the spatial mean. For a more complete description of the strengths and limitations of this type of analysis, see van den Heever (2011).

The summed contributions to the PW storage by each term in Eq. (3) are illustrated in Figure 5 as a function of PW. Again, it will be noted that, as with all figures and much of the discussion, this figure does not include results from SST300, as trends are monotonic. The integration of the curves shown over the entire range of $\mathrm{PW}$ is equivalent to the domain average. The domain-integrated storage term is sufficiently close to zero, as expected at equilibrium, as is the integrated ADV + DIV. Thus for the domain-mean balance at equilibrium, it simply follows that total evaporation equals total precipitation $(E=P)$. By summing the contributions within each PW bin, the results show the contributions weighted by their mean value within each bin and the number of points that fall into that bin. As a note, the distribution of PW looks much like the distribution of the evaporation term. Highlighted with a black bar in Figure 5 is the value of PW above which precipitation contributes significantly to the water budget $\left(\mathrm{PW}_{\text {thresh }}\right)$. These values
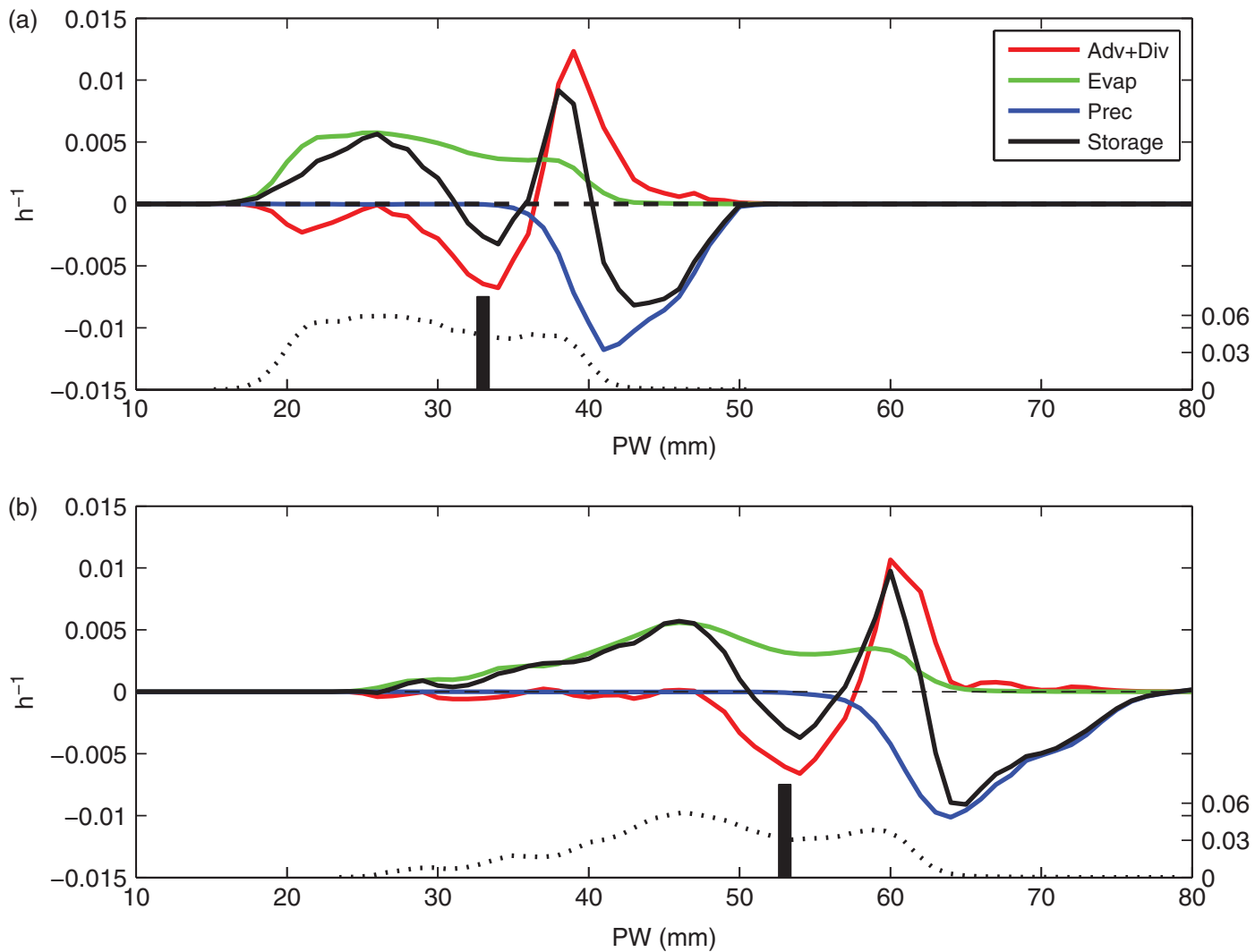

Figure 5. Summed WV flux in $\mathrm{h}^{-1}$ binned by PW. The upper panel is SST298 and the lower SST302. The red line shows contributions from atmospheric motions. Positive (negative) values mean net gains (losses). The green line shows contributions due to evaporation (always positive). The blue line shows evacuation of WV

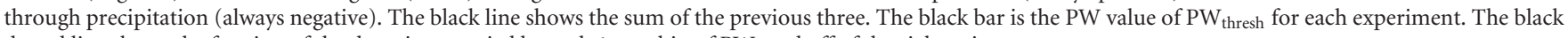
dotted line shows the fraction of the domain occupied by each $1 \mathrm{~mm}$ bin of PW read off of the right axis. 
are also summarized in Table 1 and correspond to the average value of $\mathrm{PW}$ for which rain falls at a rate of $0.01 \mathrm{~mm} \mathrm{~h}^{-1}$ or greater. Grid boxes with surface instantaneous rain rates greater than $0.01 \mathrm{~mm} \mathrm{~h}^{-1}$ account for approximately $99.5 \%$ of the total rainfall volume at any one time in the simulations, but these rates occur in only about a third of the total number of raining grid boxes. This result is both similar to climate models, in that very light rain occurs more frequently than in nature (Stephens et al., 2010), and different, in that, unlike climate models, the majority of accumulation occurs as the result of the heaviest rain and drizzle (defined below) percentiles. The $0.01 \mathrm{~mm} \mathrm{~h}^{-1}$ criterion thus serves to screen out surface grid boxes that are raining at very light intensities that do not contribute to the local water balance in any significant way. In this context, $\mathrm{PW}_{\text {thresh }}$ is similar in some ways to the critical PW concept introduced by Neelin et al. (2009) and pursued further in Posselt et al. (2012). True critical PW values correspond approximately to those values at which storage becomes zero, as theory would predict. $\mathrm{PW}_{\text {thresh }}$ is inherently a lower valued quantity than the critical PW.

The analysis of the model results presented in Figure 5 reveals the following general characteristics of the water balance at equilibrium.

(i) While there is negligible total storage over the entire domain, local regions experience significant moistening or drying that balance in space and time. Since PW has a clear spatial structure (Figure 1), it follows that binning into specific PW ranges also corresponds approximately to grouping the data by moist and dry region. There are two ranges of PW within each experiment that exhibit moistening (positive storage) offset by two ranges of PW that exhibit drying. Thus, it makes sense to think of moistening as being the result of two different mechanisms. Moistening of most of the model domain ( $\mathrm{PW}<\mathrm{PW}_{\text {thresh }}$ ) results from evaporation from the model ocean surface, whereas moistening of the wettest areas $\left(\mathrm{PW}>\mathrm{PW}_{\text {thresh }}\right)$ occurs from moisture convergence into these wetter portions of the domain. Drying likewise occurs via two different pathways, with drying occurring between the drier and wetter portions of the models via moisture divergence/advection from the dry regions themselves. The second drying mechanism in the wettest regions of the model is (primarily convective) precipitation, which inhibits the possibility of runaway moistening effects on the balance. The transitions between many of these mechanisms occur on spatial scales much smaller than those simulated in GCMs. However, the most significan differences between moist and dry regions and the relative importance of evaporation to precipitation should be well captured. Many of these results are also seen in van den Heever (2013).

(ii) Evaporation from the ocean surface, driven by the larger scale convectively forced circulation and the localscale winds associated with the convection in the lower troposphere (e.g. Pakula and Stephens, 2009), is the principal source of moistening over most of the domain. In the moist regions of the domain above $\mathrm{PW}_{\text {thresh }}$, the budget is primarily influenced by the drying effects of precipitation, moistening by ADV + DIV and evaporation driven by winds associated with convection and their cold pools within moist regions. The areal extent (insofar as PW space is representative of such a thing) of influence of this evaporation increases significantly with increasing SST. This is due primarily to the change in the distribution of PW values between the simulations. To a very good approximation, the distribution of the evaporation term is qualitatively similar to that of PW overall.

(iii) While the general behaviour of the PW storage and the contributions to it is essentially independent of SST, the quantitative details of these contributions change with SST. The entire behaviour shifts to larger PW values with higher SSTs, as might be anticipated from the CC relation. Indicative of this shift is the increase in the value of $\mathrm{PW}_{\text {thresh }}$ by 12.5 and $10.5 \% \mathrm{~K}^{-1}$ with respect to surface temperature.

Analyzing the water budget here serves several ends. The analysis shows the intimate relationship between convection and the mean state in subtle ways. For example, ADV + DIV in this context results purely from flows driven by convection over homogeneous SST with no rotation. As such, analyzing these terms with respect to global mean flows, as might necessarily be done when examining GCM results, only captures part of the story. Also, the shifts of various terms with SST serve to emphasize the nonlinear nature of such changes.

\section{Changes in precipitation characteristics with SST}

Changes to the domain mean precipitation with SST also follow expected behaviour. More total rain falls in the SST302 experiment than in either the SST298 or SST300 experiments, with increases in precipitation from SST298 to SST300 of 1.51 and $1.55 \% \mathrm{~K}^{-1}$ from SST300 to SST302, when defined with respect to the tropospheric mean temperature. The ratio of the change in precipitation to change in PW, introduced as global precipitation efficiency by Stephens and Ellis (2008), varies from 0.29 from SST298-SST300 to 0.23 from SST300-SST302. This is similar to the range of efficiencies derived from an ensemble of GCM climate-warming experiments, thus highlighting the fact that the behaviour of our RCE experiments and GCM-based climate-change experiments is similar in this respect. The reason for the approximately $20 \%$ smaller efficiency from the SST300-SST302 experiments is the nearly constant increase in all-sky cooling with warming $\left(\sim 1.9 \mathrm{~W} \mathrm{~m}^{-1} \mathrm{~K}^{-1}\right)$ and the greater values and magnitude of increase of PW between SST300 and SST302 $\left(\sim 5.1 \mathrm{~mm} \mathrm{~K}^{-1}\right)$ compared with SST298-SST300 $\left(\sim 4.3 \mathrm{~mm} \mathrm{~K}^{-1}\right)$, due to the nonlinearity of CC and the higher RH. Finally, it will be noted that the increases in precipitation are not very different from those in other simulations conducted with $2 \mathrm{~K}$ increases in SST and no increase in $\mathrm{CO}_{2}$ at $\sim 3 \% \mathrm{~K}^{-1}$ of surface warming (Sugi and Yoshimura, 2004; Held and Zhao, 2011). Increasing SSTs does not provide a perfect corollary to global warming scenarios that include both increases in $\mathrm{CO}_{2}$ and, eventually, increases in surface temperature. Increasing $\mathrm{CO}_{2}$ changes the cooling structure of the atmosphere and thus the precipitation.

The shift of the distribution of precipitation with increasing SST also resembles the changes noted in GCM experiments (Pall et al., 2007; Liu et al., 2012). This change in character is highlighted in Figure 6, showing the rain rates for both the 298 and $302 \mathrm{~K}$ experiments binned by the respective percentile of the distribution (dot-dashed and grey lines respectively). The solid black line is the percent per $\mathrm{K}$ increase of rain rate for each percentile bin. At the percentiles for which this line is positive (above $\sim 97 \mathrm{th}$ ), the rain rates are higher in SST302 than in SST298. This implies that

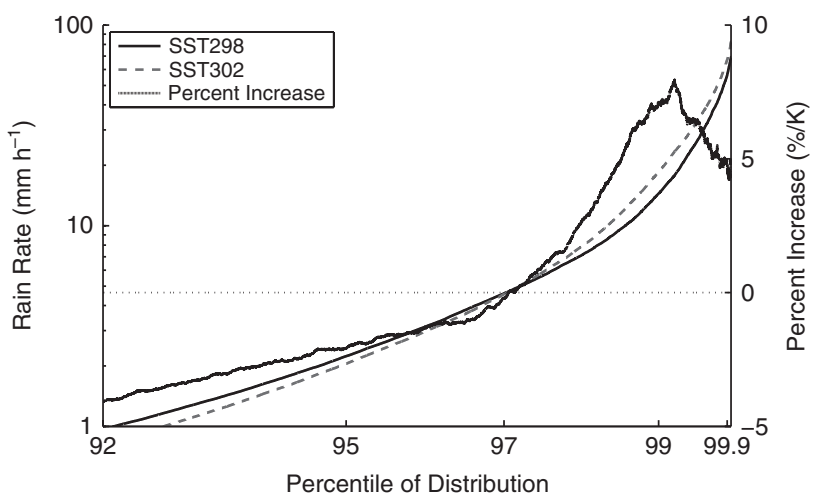

Figure 6. Modelled rain rates binned by model respective percentile read off the left axis. SST298 is shown by the dot-dashed line and SST302 by the grey. On the right axis, the solid black line is the percentage difference between the two simulations. 

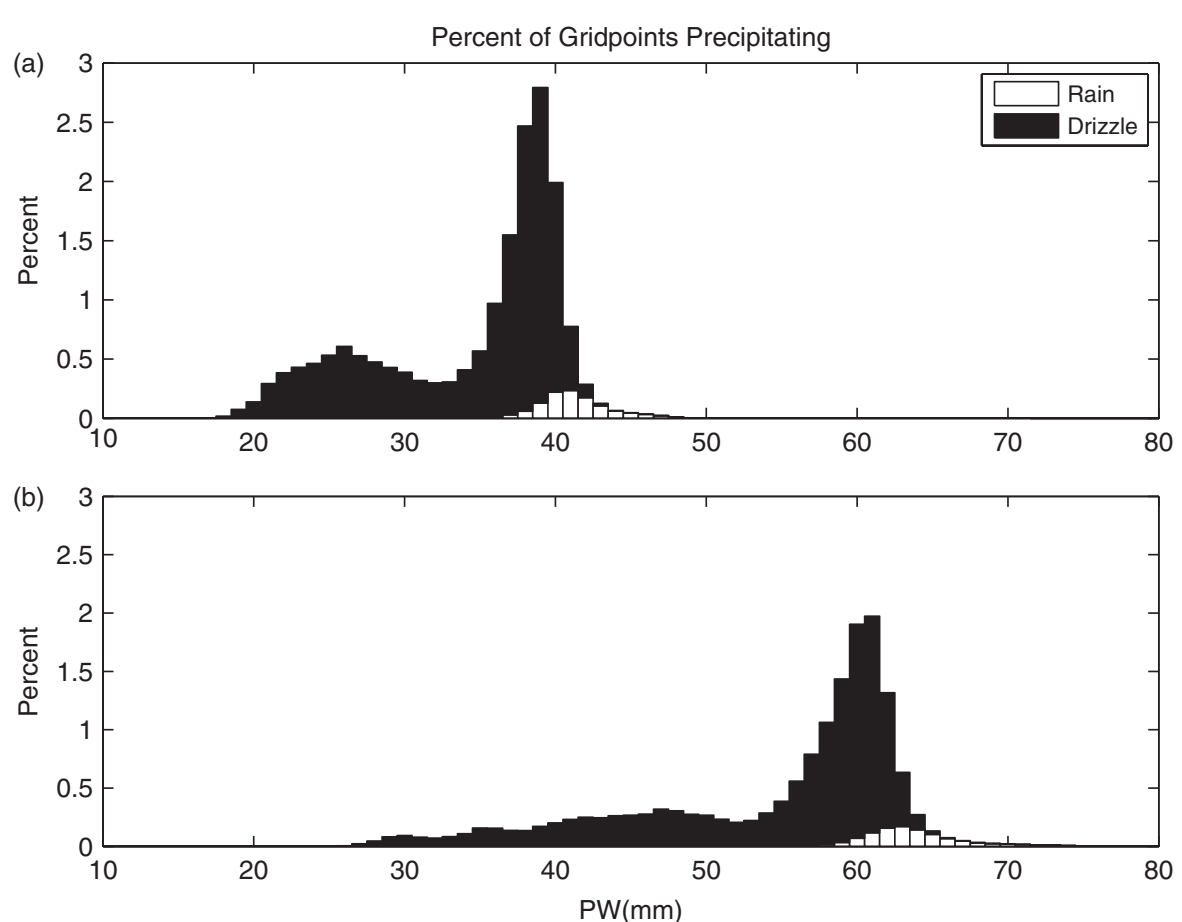

Figure 7. The percentage of surface grid points exhibiting rain (white) or drizzle (black). The upper panel, (a), is for SST298 and the lower, (b), for SST302.

the heaviest rain rates increase in frequency with increasing SST. Thus, SST302 rains more frequently at rates in excess of $6 \mathrm{~mm} \mathrm{~h}^{-1}$, at the apparent expense of rain rates less than that. The increase in rain rates at the heaviest percentiles approximates the CC-implied increase of $\sim 7 \% \mathrm{~K}^{-1}$. A similar kind of behaviour is noted in general circulation models (Pall et al., 2007; Turner and Slingo, 2009), although not in all models (Sugiyama et al., 2010). From the figure it can be seen that more than $90 \%$ of the total grid points have rates of less than $1 \mathrm{~mm} \mathrm{~h}^{-1}$ (which we call 'drizzle'). There are $4 \%$ fewer drizzling pixels in the SST302 experiment compared with the SST298 experiment. It should be noted that these results are different from those of Muller et al. (2011), who saw rain rates increase at every percentile, probably because their frequency of precipitation was invariant with SST, while we observe decreasing frequency with increasing SST.

The characteristics of the distribution of rain (as above, greater than $1 \mathrm{~mm} \mathrm{~h}^{-1}$ or $\sim 93 \mathrm{rd}$ percentile from Figure 6) and drizzle (less than $1 \mathrm{~mm} \mathrm{~h}^{-1}$ ) are also examined as a function of PW, as shown in Figure 7(a) and (b). Figure 7(a) shows the percentage of modelled grid points in each $\mathrm{PW}$ bin that are raining (white) and drizzling (black) for SST298. The coolest experiment is seen to exhibit a bimodal distribution in drizzle, with a small peak at the lowest PW values and a global maximum overlying the unimodal distribution of rain. The distribution of drizzle in SST302 shows that it slowly ramps up past a very weak, local peak at $48 \mathrm{~mm}$ before peaking at $62 \mathrm{~mm}$. The PW values at which the peaks in drizzle occur approximate the PW values of the rapid transition to high rain rates noted in Posselt et al. (2012). This is no coincidence, as the abrupt transition to heavy rain would imply a general cessation of drizzle. The rain distribution also seems to be flatter and wider in the warmer SST case. Figure 7(b) shows that the occurrence of rain shifts toward higher PW with increasing SST, as would be expected with an increase in tropospheric temperature. What is truly remarkable here is the influence of drizzle at the surface compared with rain and the way in which it changes. Drizzle seems to have a dry region peak in SST298, likely produced in association with shallow cumulus clouds, while in SST302 the drizzle does not increase significantly until PW values characteristic of the edges of moist regions (see Figure 1). This could signify a shift in drizzle production toward congestus clouds at the expense of shallow convection in SST302. These shifts are also a function of the distribution of PW organizing in such a way. Alternatively, this shift could imply a change in the convectively driven mean circulation and the role of subsidence drying on grid boxes prone to drizzling rain rates, although the weakening of the mean circulation, as shown in Posselt et al. (2012), would seem to implicate local effects as driving this change. Such subtle effects and, hence, results would be difficult to capture in general circulation models.

\section{Moist-static energy}

Moist-static energy (MSE: Riehl and Malkus, 1958) can be formulated as

$$
\mathrm{MSE}=c_{\mathrm{p}} T+L q+g z,
$$

where $c_{\mathrm{p}}$ is the isobaric specific heat of air, $T$ is temperature, $L$ is the latent heat of vaporization, $q$ is the total water mixing ratio, $g$ is the gravitational constant and $z$ is height. It has been used in a variety of contexts to understand the energy distribution of the tropical atmosphere. Here it will be used as a tool to assess the distribution of the states of the modelled atmospheres. Figure 8(a) illustrates the horizontal-mean, vertical profiles of MSE in both SST298 and SST302. Figure 8(b) shows PDFs of column MSE normalized by the respective simulation mean column MSE for both SST298 and SST302. The normalization is done to ease comparison. The PDF in Figure 7(b) is and those in Figure 7(c)-(d) are, therefore, unitless. For reference, the column mean MSE values in SST298 and SST302 are $1.25 \times 10^{7}$ and $1.29 \times 10^{7} \mathrm{~J}$, respectively. The increase is the result of higher temperature and higher watervapour concentrations, as discussed above, in SST302. Figure 8(b) shows a marked difference in the character of the column MSE in the two model runs examined. In SST298, the distribution is narrow and maximizes left of the mean with a local maximum just to the right of it. In SST302, the distribution is much more complex. There are two prominent peaks, one just less than the mean and one much greater than it, as well as a variety of local maxima in the left tail. What is especially interesting is the juxtaposition of the SST298 and SST302 distributions.

To understand the contributions to these differences, Figure $8(\mathrm{c})$ shows the PDF of the moisture term $(L q)$. This term has the shape that it does because of the relative populations of dry and moist columns. The dry end of the SST302 distribution likely obtains lower values due to the role of subsidence drying, which is less dependent on SST than other aspects of the environmental physics. The moisture contributions to MSE appear to explain 

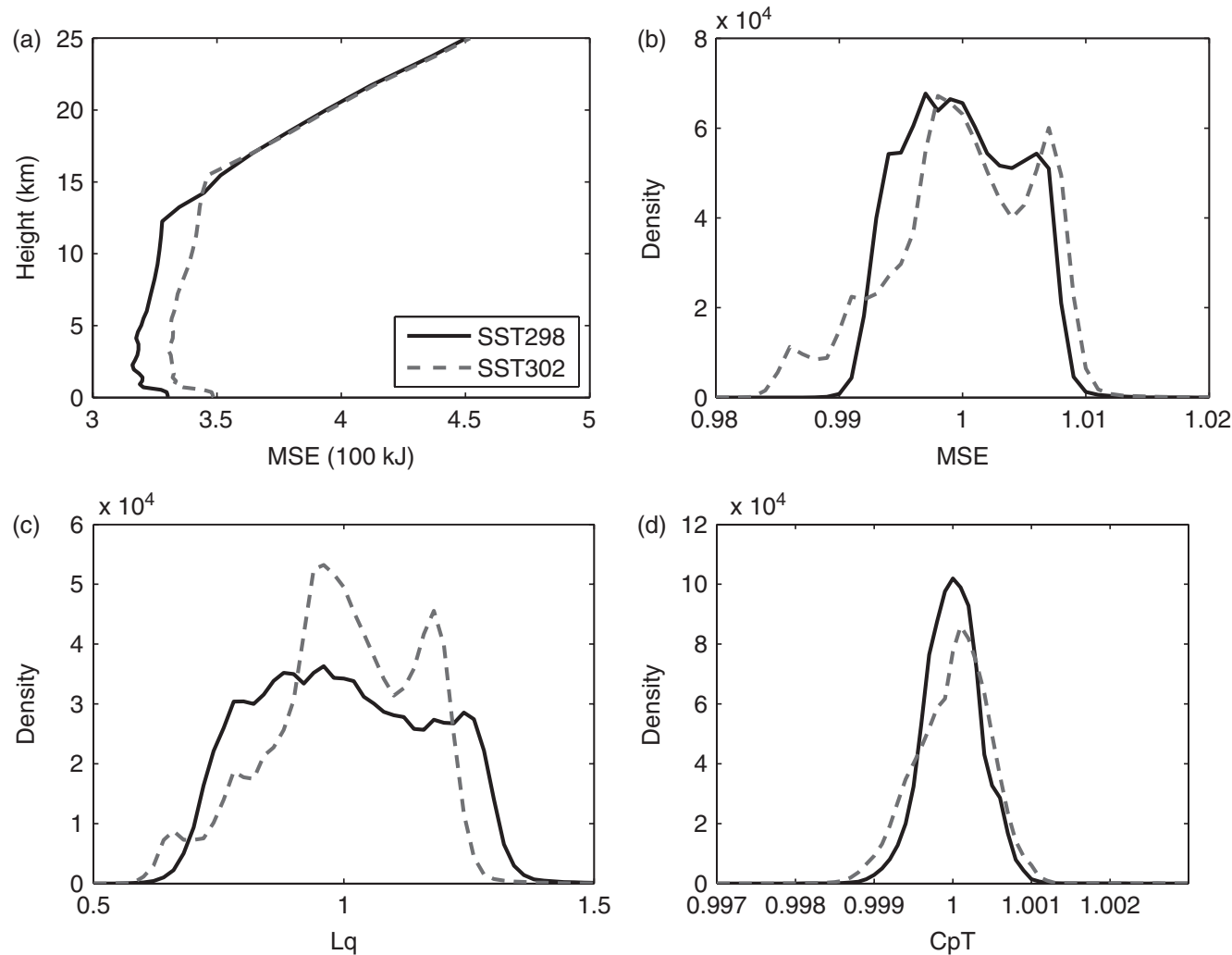

Figure 8. (a) Mean profiles of MSE for SST298 (solid) and SST302 (dashed). (b) PDFs of total column integrated MSE in SST298 and SST302, normalized by their respective means. (c) PDFs of the $L q$ (moisture) term to the total MSE, again normalized by the model run respective mean. (d) PDFs of the $c_{\mathrm{p}} T$ (temperature) term to the total MSE.

most of the characteristics of the distributions of total MSE. However, clearly not all of the characteristics of total MSE in Figure $8(\mathrm{a})$ are explained by the moisture variation in Figure 8(b). The PDF of temperature contributions $\left(c_{\mathrm{p}} T\right)$ to column MSE exhibits very little spread (Figure $8(\mathrm{~d})$ ). In fact, the standard deviations are only $3.54 \times 10^{-4}$ and $4.57 \times 0^{-4} \mathrm{~J}$ for SST298 and SST302, respectively. Both distributions of $c_{\mathrm{p}} T$ are unimodal about the normalized mean but, given the standard deviations, the SST302 distribution is slightly wider. The result of this is that while the PDF of the moisture component is wider and flatter in SST298 when combined with the narrower temperature PDF, these contributions co-vary in such a way as to narrow the normalized PDF of total MSE in SST298 relative to SST302. It should be noted that the wider SST302 distribution is another indication of the enhanced extremes (warmer/moister and drier/cooler) with warmer SSTs. Anomalous MSE increases at both the high and especially the low-end tails of the distribution. The distribution of energy in the atmosphere is both a thermodynamic and a convective result (i.e. the atmosphere is in RCE). Since there are no external organizing influences imposed on the simulation such as shear, SST gradients or patterns or equatorial waves, it may safely be assumed that the mechanisms behind the co-variation of the components with mean MSE are convective in origin. If this is true, resolving convection would then be crucial to modelling frequent and infrequent states and their partitioning in the atmosphere under warming conditions.

\section{Discussion and conclusions}

This article reports on the results of radiative-convective equilibrium experiments designed to examine how the equilibrium state changes with increasing lower boundary SST. The experiments were performed using a state of the art cloud-systemresolving model that is integrated over a large model domain and over periods long enough that a state of radiative convective equilibrium is established. An important consideration for these simulations, unlike climate model simulations, is that convective systems were resolved, thus avoiding the need for the use of convection parametrization schemes. These convectivescale feedbacks shape the equilibrium state of the experiments and, we argue, are not likely to exist in current climate models given the need for convection parametrization schemes.

The major conclusions of the work presented here are the following.

(i) When compared with the increase in SST, the domainmean PW appears to increase at a rate greater than that predicted by CC. In fact, the domain-mean PW increases at nearly the CC rate, but only when measured against the troposphere mean temperature (Table 1). This indicates that the rate of increase in atmospheric water-vapour content is not governed solely by the characteristics of the surface but instead is sensitive to the fine-scale vertical structure of the atmospheric warming (Figure 2). In the experiments examined here, the vertical structure in turn is largely influenced by the effects of convection on its surrounding environment. Ultimately, the characteristics of convection are a function of PW and PW gradients. This forms a convective feedback loop, which GCMs are unlikely to model on the relevant scales.

(ii) The RCE state is characterized by areas of moistening and drying that are sustained by a mean, radiatively forced and convectively driven troposphere-deep overturning circulation that connects them (e.g. Stephens and Ellis, 2008). This mean overturning circulation, reflected in the mean surface wind speed and mean convective vertical mass flux (Posselt et al., 2012), slows with increasing SST in a manner similar to that observed in GCM experiments (e.g. Vecchi and Soden, 2007). The moisture budgeting (Figure 5) illustrates the disparate nature of moisture storage and its contributing terms as SSTs warm.

(iii) While GCM simulations indicate a near-constant column relative humidity with increasing SST, our experiments show a slight increase in near-surface RH and a significant increase in upper tropospheric RH. Since this change in $\mathrm{RH}$ is not a function of the basic-state equilibrium, it must 
be a result of differences in convective processes between the runs, especially those of convective detrainment. It was also suggested that, due to constraints on the longwave cooling ability of the atmosphere, the $\mathrm{RH}$ must increase, since domain-mean PPE increases only slightly between simulations. This result is a function of convectivescale processes and illustrates that a control process other than large-scale circulation changes may be important in predicting $\mathrm{RH}$ changes under warming scenarios. This suggests that RH trends in GCMs might lack a contributing component.

(iv) Changes to the domain-mean precipitation with SST follow the expected behaviour. The response of the RCE experiments to increasing SST is very similar to the responses of the AR4 models to warming. Precipitation increased from the SST298-SST300 experiments by 1.51 and $1.55 \% \mathrm{~K}^{-1}$ per degree of tropospheric mean warming from SST300-SST302, when defined with respect to the tropospheric mean temperature. The global precipitation efficiency as defined by Stephens and Ellis (2008) varies from 0.29 and 0.23 respectively, which is similar in range to the precipitation efficiency derived from the ensemble of GCM climate-warming experiments (Stephens and Ellis, 2008). This confirms the earlier suggestions of Stephens and Ellis (2008) that the magnitude of precipitation change, defined in terms of precipitation efficiency, is a robust feature of such systems in energy balance. The reason for the smaller efficiency from SST300 to SST302 experiments is due to the nonlinearity in increasing PW and similar change in all-sky cooling between the two experiments and SST300. This decreased emission with increased warming is a consequence of nonlinear effects of the curve of growth of water-vapour emission and suggests that the global precipitation efficiency will continue to decrease as warming increases.

(v) The distribution of precipitation also shifts with increasing SST in a way that resembles the changes noted in GCM experiments. Precipitation appears to intensify with warming and increases in rain rates greater than approximately $6 \mathrm{~mm} \mathrm{~h}^{-1}$ (Figure 6) occur at the expense of lighter rain rates (less than $6 \mathrm{~mm} \mathrm{~h}^{-1}$ ). This increase in more intense rain follows at a rate similar to, but slightly less than, the CC rate of increase of vapour (Table 1), a characteristic also noted with respect to climate model simulations (Pall et al., 2007). However, in these experiments the shift is likely due to convectivescale effects, unlike in climate models, where this shift is due primarily to larger-scale mean flows.

(vi) The distributions of column MSE appear to be different in the warmest state compared with the coldest. Why they are so different is not completely apparent, but, given the characteristically different distributions of the moisture term, the shifts in the water-vapour budget and how they contribute to PW must yield these differences. The temperature and moisture contributions to total column MSE in SST302 appear to co-vary in such a way as to result in a wider total distribution. This yields a wider final distribution and the interesting result that normalized integrated MSE is not constrained to a certain distribution shape, even though the mean profiles (Figure $8(\mathrm{a})$ ) are nearly identical, though shifted. This may simply imply that RCE is really an MSE result (vertical profiles similar), while the way in which RCE is reached is inherently defined by the convection (PDFs, especially of $L q$ terms, are different). If this is indeed the case, then resolving clouds and cloud systems would be a crucial part of simulating the tropical atmosphere accurately, as simply modelling the mean convection in the way that parametrizations are defined to do may never simulate all local aspects of any single environment correctly at subgrid scales. Particularly noteworthy are the differences between the MSE and rain distributions. A priori it might be assumed that these would be similar, given the convective response to MSE, but this is clearly not the case in either SST298 or SST302.

What these results imply, in general, is that to predict the convective-scale responses of the atmosphere to surface warming accurately, models need to contain an explicit representation of cloud systems. An effort has been made to this end by embedding a cloud model into a general circulation model (Khairoutdinov et al., 2005), but this framework is only likely to approximate the results presented here, given its current limitations especially and that the two-dimensional geometry of the embedded cloudresolving model will affect the convective organization artificially (Tompkins, 2000). The smallest scale features resolved in these RCE experiments (for the first time over such a large area) are likely to feed upscale into processes currently assumed to be well resolved in climate models. The RH profile (Figure 3) illustrates the importance of detrainment, one such process. Also, taken together, ((i)-(vi)) indicate that convection is not just a response to, or modification of, the thermodynamically implied warming, but integral to the warmer atmospheric state. Convection affects everything from the large-scale organization of energy and moisture to the nature of how local-scale processes (e.g. rain rates) deal with surpluses or deficits thereof.

The potential importance of some of the results will be explicitly stated. Rain and its partitioning between light rain and heavy, high-percentile rain is the part of the climate system most often felt by mankind and it is therefore critical to begin to understand shifts in such processes with changing climates. Here we see a shift away from rain occurring in low PW regions toward rain in high PW regions reflective of the rich-get-richer mechanism (Chou and Neelin, 2004). As such, there is a shift not just in the frequency and intensity of precipitation but also in the location. The important impacts of weather occur in the tails of the statistical distributions of occurrences such as temperature and precipitation. These tails are likely to be difficult for GCMs to capture in the sense that we have here. Acknowledging the limitations inherent in such idealized simulations, we nevertheless argue that understanding these extremum events is better achieved from the types of experiments presented here, with their unique combination of high resolution over a large domain and long temporal integration.

One of the strengths of the RCE framework exploited in this study is that a fixed SST allows us to examine the response of the atmosphere to surface warming. However, this is also a limitation, since the real-world ocean responds to changes in the atmospheric temperature and amount of solar and infrared radiative flux. It is impossible, due to the nonlinearity inherent in the interaction between clouds, radiation and surface properties, to determine a priori how the ocean might respond in each of our experiments if SST were allowed to vary interactively. For example, there is an increase in high cloud fraction between SST298 and SST302 (Posselt et al., 2012) that is associated with a decrease in downwelling short-wave radiation at the surface (not shown), which would imply cooling of the upper ocean and a negative feedback in a manner hypothesized by Ramanathan and Collins (1991). However, the decrease in mean surface wind speed with SST leads to a decrease in the wind-generated influence of evaporation, a consequently smaller increase in surface latent heat release between SST298 and SST302 and positive feedback. The only way to deconvolve the interaction between competing influences is to run the simulations with an interactive ocean. Another limitation of this study is that no subtropical feedbacks into the tropical atmosphere occur. The degree to which this lack of tropical-subtropical interaction affects our results is impossible to say. Despite these limitations, the current study demonstrates the usefulness of large-scale RCE simulations such as those examined here. Also implicated is the potential importance of including physical cloud processes in simulating a mean atmospheric environment fully. 


\section{Acknowledgements}

This work was supported by NASA CloudSat grant 5-319160. S. van den Heever was supported by NASA grant 49683. A. D. Posselt was supported by NASA Modelling, Analysis, and Prediction grant NNX09AJ43G. The authors thank two anonymous reviewers who helped to make this document more precise.

\section{References}

Allen MR, Ingram WJ. 2002. Constraints on future changes in climate and the hydrologic cycle. Nature 419: 224-232.

Bretherton CS, Peters ME, Back LE. 2004. Relationships between water vapour path and precipitation over the tropical oceans. J. Climate 17: 1517-1528.

Bretherton CS, Blossey PN, Khairoutdinov M. 2005. An energy-balance analysis of deep convective self-aggregation above uniform SST. J. Atmos. Sci. 62 : 4273-4292.

Chou C, Neelin JD. 2004. Mechanism of global warming impacts on regional tropical precipitation. J. Climate 17: 2688-2701.

Cotton WR, Pielke RA Sr, Walko RL, Liston GE, Tremback CJ, Jiang H, McAnelly RL, Harrington JY, Nicholls ME, Carrio GG, McFadden JP. 2003. RAMS 2001: current status and future directions. Meteorol. Atmos. Phys. 82 $5-29$.

Grabowski WW, Moncrieff MW. 2001. Large-scale organization of tropical convection in two-dimensional explicit numerical simulations. Q. J. $R$ Meteorol. Soc. 127: 445-468.

Groisman PY, Knight RW, Easterling DR, Karl TR, Hegerl GC, Razuvaev VAN 2005. Trends in intense precipitation in the climate record. J. Climate 18 $1326-1350$.

Harrington JY. 1997. The effects of radiative and Microphysical processes on simulated warm and transition season arctic Stratus, Ph.D. Thesis, 298pp Colorado State University: Fort Collins, CO.

Hartmann DL, Larson K. 2002. An important constraint on tropical cloudclimate feedback. Geophys. Res. Lett. 29: 1951, DOI: 10.1029/2002GL015835.

van den Heever SC. 2011. The impacts of aerosol indirect forcing on dynamical aspects of deep convection. Fall Meeting. American Geophysical Union: San Francisco, CA.

van den Heever SC, Stephens GL, Wood NB. 2011. Aerosol indirect effects on tropical convections characteristics under conditions of radiative-convective equilibrium. J. Atmos. Sci. 68: 699-718.

van den Heever SC. 2011. Aerosol indirect forcing on the precipitable water budget of the Tropics. The 91st American Meteorological Society Annual Meeting, AMS, J14.2. 23-27 January 2011, Seattle, WA.

Held IM, Hemler RS, Ramaswamy V. 1993. Radiative-convective equilibrium with explicit two-dimensional moist convection. J. Atmos. Sci. 50 3909-3927.

Held IM, Soden BJ. 2000. Water-vapour feedback and global warming. Ann. Rev. Energy Environ. 25: 441-475.

Held IM, Soden BJ. 2006. Robust responses of the hydrological cycle to globa warming. J. Climate 19: 5686-5699.

Held IM, Zhao M. 2011. The response of tropical cyclone statistics to an increase in $\mathrm{CO}_{2}$ with fixed sea surface temperature. J. Climate 24: 5353-5364.

Hill GE. 1974. Factors controlling the size and spacing of cumulus clouds as revealed by numerical experiments. J. Atmos. Sci. 31: 646.

Igel MR. 2011. 'A tropical radiation and cloud system feedback modulated by sea surface temperatures', Master's thesis, $79 \mathrm{pp}$. Colorado State University: Fort Collins, CO.

Johnson RH, Rickenbach TM, Rutledge SA, Ciesielski PE, Schubert WH. 1999. Trimodal characteristics of tropical convection. J. Climate 12: 2397-2418.

Khairoutdinov M, Randall D, DeMott C. 2005. Simulations of the atmospheric general circulation using a cloud-resolving model as a superparameterization of physical processes. J. Atmos. Sci. 62: 2136-2154.

Lilly DK. 1962. On the numerical simulation of buoyant convection. Tellus XIV: $148-172$.

Liu CR, Allan P, Huffman GJ. 2012. Co-variation of temperature and precipitation and CMIP5 models and satellite observations. Geophys. Res. Lett. 39: L13803, DOI: 10.1029/2012GL052093.

Luo ZJ, Kley D, Johnson RH, Liu GY, Nawrath S, Smit HGJ. 2012. Influence of sea surface temperature on humidity and temperature in the outflow of tropical deep convection. J. Climate 25: 1340-1348.

Meehl GA, Stocker TF, Collins WD, Friedlingstein P, Gaye T, Gregory JM, Kitoh A, Knutti R, Murphy JM, Noda A, Raper SCB, Watterson IG Weaver AJ, Zhao ZC. 2007. Global climate projections. In Climate Change 2007: The Physical Scientific Basis, Solomon S, Qin D, Manning M, Chen Z Marquis M, Averyt KB, Tignor M, Miller HL. (eds): 747-845. Cambridge University Press: Cambridge.

Muller CJ, O'Gorman PA. 2011. Intensification of precipitation extremes with warming in a cloud-resolving model. J. Climate 24: 2784-2800.

Neelin JD, Peters O, Hales K. 2009. The transition to strong convection. J. Atmos. Sci. 66: 2367-2384.

O'Gorman PA, Muller CJ. 2010. How closely do changes in surface and column water vapour follow Clausius-Clapeyron scaling in climate change simulation? Environ. Res. Lett. 5: 025207, DOI: 10.1088/17489326/5/2/025207.

Pakula L, Stephens GL. 2009. The role of radiation in influencing tropical cloud distributions in a radiative-convective equilibrium cloud-resolving model. J. Atmos. Sci. 66: 62-76.
Pall P, Allen MR, Stone DA. 2007. Testing the Clausius-Clapeyron constraint on changes in extreme precipitation under $\mathrm{CO}_{2}$ warming. Clim. Dyn. 28 : $351-363$.

Paltridge G, Arking A, Pook M. 2009. Trends in middle- and upper-level tropospheric humidity from NCEP reanalysis data. Theor. Appl. Climatol. 98: $351-359$.

Posselt DJ, van den Heever SC, Stephens GL. 2008. Trimodal cloudiness and tropical stable layers in simulations of radiative convective equilibrium. Geophys. Res. Lett. 35: L08802, DOI: 10.1029/2007GL033029.

Posselt DJ, van den Heever SC, Stephens GL, Igel MR. 2012. Changes in the interaction between tropical convection, radiation and the large scale circulation in a warming environment. J. Climate 25: 557-571.

Ramanathan V, Collins W. 1991. Thermodynamic regulation of ocean warming by cirrus clouds deduced from observations of the 1987 El Nino. Nature 351: $27-32$.

Richter I, Xie SP. 2008. Muted precipitation increase in global warming simulations: a surface evaporation perspective. J. Geophys. Res. 113: D24118, DOI: 10.1029/2008JD010561.

Riehl H, Malkus JS. 1958. On the heat balance in the equatorial trough zone. Geophysica 6: 505-535.

Rondanelli R, Lindzen RS. 2008. Observed variations in convective precipitation fraction and stratiform area with sea surface temperature. J. Geophys. Res. 113: D16119, DOI: 10.1029/2008JD010064.

Saleeby SM, Cotton WR. 2004. A large-droplet mode and prognostic number concentration of cloud droplets in the Colorado State University Regional Atmospheric Modelling System (RAMS). Part I: module descriptions and supercell test simulations. J. Appl. Meteorol. Climatol. 43: 182-195.

Saleeby SM, van den Heever SC. 2013. Developments in the CSU-RAMS aerosol model: emissions, nucleation, regeneration, deposition, and radiation. J. Appl. Meteorol. Climatol., DOI: 10.1175/JAS-D-12-076.1.

Santer BD, Mears C, Wentz FJ, Taylor KE, Gleckler PJ, Wigley TML, Barnett TP, Boyle JS, Brueggemann W, Gillett NP, Klein SA, Meehl GA, Nozawa T, Pierce DW, Stott PA, Washington WM, Wehner MF. 2007. Identification of human-induced changes in atmospheric moisture content. Proc. Natl. Acad. Sci. USA 104: 15248-15253.

Seager R, Naomi N, Vecchi GA. 2010. Thermodynamic and dynamic mechanisms for large-scale changes in the hydrological cycle in response to global warming. J. Climate 23: 4651-4668.

Sherwood SC, Ingram W, Tsushima Y, Satoh M, Roberts M, Vidale PL, O'Gorman PA. 2010. Relative humidity changes in a warmer climate. J. Geophys. Res. 115: D16119, DOI: 10.1029/2009JD012585.

Smagorinsky J. 1963. General circulation experiments with the primitive equations. Part I, the basic experiment. Mon. Weather Rev. 91: 99-164.

Soden BJ, Fu R. 1995. A satellite analysis of deep convection, upper-tropospheric humidity, and the greenhouse-effect. J. Climate 8: 2333-2351.

Soden BJ, Jackson DL, Ramaswamy V, Schwarzkopf MD, Huang XL. 2005 The radiative signature of upper tropospheric moistening. Science 310: $841-844$.

Stephens GL, Ellis TD. 2008. Controls of global-mean precipitation increases in global warming GCM experiments. I. Climate. 21: 6141-6155.

Stephens GL, Hu YX. 2010. Are climate-related changes to the character of global-mean precipitation predictable? Environ. Res. Lett. 5: 025209, DOI: 10.1088/1748-9326/5/2/025209.

Stephens GL, L'Ecuyer T, Forbes R, Gettlemen A, Golaz JC, Bodas-Salcedo A, Suzuki K, Gabriel P, Haynes J. 2010. Dreary state of precipitation in models. J. Geophys. Res. 115: D24211, DOI: 10.1029/2010JD014532.

Storer RL, van den Heever SC. 2013. Microphysical processes evident in aerosol forcing of tropical deep convection. J. Atmos. Sci. 70: 430-446.

Sugi M, Yoshimura J. 2004. A mechanism of tropical precipitation change due to $\mathrm{CO}_{2}$ increase. J. Climate 17: 238-243.

Sugiyama M, Shiogama H, Emori S. 2010. Precipitation extreme changes exceeding moisture content increases in MIROC and IPCC climate models. Proc. Natl. Acad. Sci. USA 107: 571-575.

Tompkins AM. 2000. The impact of dimensionality on long-term cloudresolving model simulations. Mon. Weather Rev. 128: 1521-1535.

Tompkins AM. 2001. Organization of tropical convection in low vertical wind shears: the role of water vapour. J. Atmos. Sci. 58: 529-545.

Trenberth KE, Fasullo J, Smith L. 2005. Trends and variability in columnintegrated atmospheric water vapour. Clim. Dyn. 24: 741-758.

Turner AG, Slingo JM. 2009. Uncertainties in future projections of extreme precipitation in the Indian monsoon region. Atmos. Sci. Lett. 10: 152-158, DOI: $10.1002 /$ asl.223.

Vecchi GA, Soden BJ. 2007. Global warming and the weakening of the tropical circulation. J. Climate 20: 4316-4340.

Walko RL, Band LE, Baron J, Kittel TGF, Lammers R, Lee TJ, Ojima D, Pielke RA, Taylor C, Tague C, Tremback CJ, Vidale PL. 2000. Coupled atmosphere-biophysics-hydrology models for environmental modelling. J. Appl. Meteorol. 39: 931-944.

Wentz FJ, Ricciardulli L, Hilburn K, Mears C. 2007. How much more rain will global warming bring? Science 317: 233-235.

Willett KM, Gillett NP, Jones PD, Thorne PW. 2007. Attribution of observed surface humidity changes to human influence. Nature 449: 710-713.

Yano J-I, Guichard F, Lafore J-P, Redelsperger J-L, Bechtold P. 2004 Estimations of mass fluxes for cumulus parameterizations from highresolution spatial data. J. Atmos. Sci. 61: 829-842.

Zhang X, Zwiers FW, Hergel GC, Lambert FH, Gillet NP, Solomon S, Stott PA, Nozawa T. 2007. Detection of human influence on twentieth-century precipitation trends. Nature 448: 461-465. 